\title{
A preliminary assessment of guideline adherence and clinical variation in oral cancer treatment: a MarketScan database study
}

Antoine Eskander ${ }^{1 *+} \odot$, Axel Sahovaler ${ }^{1+}$, Jennifer Shin², Konrado Deutsch¹, Matthew Crowson ${ }^{1}$, Neerav Goyal ${ }^{3}$, David L. Witsell4 ${ }^{4}$ Kristine Schulz ${ }^{4}$, Neil D. Gross ${ }^{5}$, Randal Weber ${ }^{5}$, Samir S. Khariwala ${ }^{6}$, Seth Cohen ${ }^{4}$, Derek Walter CyrLee ${ }^{7,4}$ and Vikas Mehta ${ }^{8}$

\begin{abstract}
Background: To assess variations in adherence to guideline-recommended processes of care for oral cavity cancer patients.

Methods: Retrospective study using a U.S. healthcare research database (MarketScan). Index diagnoses were considered from 2010 to 2012 with follow-up from 2013 to 2014. Diagnostic and procedure codes were utilized to identify oral cavity patients with a defined treatment modality. Compliance with guideline-recommended processes of care, which included pre-treatment imaging, thyroid-function testing (TFTs), multidisciplinary consultation and gastrostomy-tube insertion rates, were assessed.
\end{abstract}

Results: A total of 2752 patients were identified. Surgery alone was the most common treatment (60.8\%), followed by surgery with adjuvant chemoradiotherapy (20.4\%) and surgery with adjuvant radiotherapy (18.8\%). Head/neck and chest imaging were obtained in $60 \%$ and $62.5 \%$ of patients respectively. Significant geographical differences in head and neck imaging were observed between North-central (64\%), South (58.4\%) and West (56.1\%) regions $(p=0.026)$. Differences in chest imaging were also present between North-east (65\%) and West (56.8\%; $p=0.007)$. TFTs were obtained in $54.4 \%$ of the patients after radiation treatment, and $18.6 \%$ of patients had multidisciplinary consultation during the 6 months before and 3 months after initiation of treatment. During the year after treatment initiation, $21.2 \%$ of patients underwent G-tube placement, with significantly higher rates in patients receiving triple modality treatment (58\%) when compared to surgery plus radiation (27\%) and surgery alone $(15 \% ; p<0.01)$.

Conclusion: Adherence to evidence-based practices was low based on the database coding. These data suggest a potential to improve adherence and increase the routine use of practices delineated in national clinical practice guidelines.

\footnotetext{
*Correspondence: antoine.eskander@mail.utoronto.ca

${ }^{\dagger}$ Antoine Eskander and Axel Sahovaler contributed equally to the

manuscript.

${ }^{1}$ Department of Otolaryngology-Head and Neck Surgery, Sunnybrook

Health Sciences Centre and the Odette Cancer Centre, University

of Toronto, 2075 Bayview Ave., M1-102, Toronto, ON M4N 3M5, Canada

Full list of author information is available at the end of the article
}

(c) The Author(s) 2021. Open Access This article is licensed under a Creative Commons Attribution 4.0 International License, which permits use, sharing, adaptation, distribution and reproduction in any medium or format, as long as you give appropriate credit to the original author(s) and the source, provide a link to the Creative Commons licence, and indicate if changes were made. The images or other third party material in this article are included in the article's Creative Commons licence, unless indicated otherwise in a credit line to the material. If material is not included in the article's Creative Commons licence and your intended use is not permitted by statutory regulation or exceeds the permitted use, you will need to obtain permission directly from the copyright holder. To view a copy of this licence, visit http://creativecommons.org/licenses/by/4.0/. The Creative Commons Public Domain Dedication waiver (http://creativeco mmons.org/publicdomain/zero/1.0/) applies to the data made available in this article, unless otherwise stated in a credit line to the data. 
Clinical relevance: This study reflects a suboptimal adherence to guidelines based on the database employed. This study should be considered by healthcare providers and efforts should be maximized to follow the processes of care which have proven to impact on patient's outcomes.

Keywords: Guideline-recommended processes of care, MarketScan, Oral cavity carcinoma

\section{Background}

Quality of care (QoC) assessment has become a priority for physicians and organizationsalike, with the objective of improving patient outcomes and experience [1]. The Donabedian model [2] provides the framework to evaluate QoC through three different categories: structure,processes of care,outcomes,

Evidence-based guidelines, including those from the National Comprehensive Cancer Network (NCCN), National Institute for Health and Care Excellence (NICE) and Cancer Care Ontario (CCO) [3-5], have been developed worldwide for the management of head and neck cancer, highlighting processes of care and designating quality indicators. Practices such as pre-treatment imaging, multidisciplinary consultation, and follow-up recommendations are endorsed. There is a paucity of literature on adherence to guidelines and their use as quality metrics. Furthermore, variations in guideline adherence by geography and treatment modality have not been fully studied. Analyzing adherence of physicians to these processes of care, may be a surrogate for QoC, and can provide insight into gaps in the quality of delivered care.

Our objective was thus to evaluate concordance with guideline-recommended processes of care in the management of oral cavity cancer patients using a large United States population-based, healthcare administrative dataset. In addition to this indirect measure of QoC, we secondarily aimed to evaluate variations in adherence and adjunct procedures in this population.

\section{Methods}

\section{Data source/study population}

The study cohort included all patients within the database who met inclusion and excluded the ones that met the exclusion criteria. Inclusion criteria were adult patients with oral cavity cancers with primary surgical treatment. Exclusion criteria were patients who received non-surgical treatment or palliative treatment. Data was obtained from the MarketScan ${ }^{\circledR}$ Commercial Claims and Encounters Database and Medicare Supplemental and Coordination of Benefits dataset (Truven Health Analytics and IBM Watson Health, Ann Arbor, MI) Analytics). This is a US healthcare database that contains individual inpatient and outpatient insurance billing claims for employees and their dependents from approximately 45 large employers covered by more than 100 commercial payers in the United States. We also accessed the Medicare supplemental databases in this study. MarketScan includes inpatient and outpatient information, demographic, diagnostic and procedural data. The database also enables longitudinal tracking of patients across different sites of care over multiple years [6-8]. This study was deemed exempt from Institutional Review Board oversight at Duke Medicine as it focuses on de-identified health information (Pro00068570).

Codes from the International Classification of Diseases, Ninth Revision, Clinical Modification (ICD-9-CM) classification system, The Current Procedural Terminology, 4th Edition (CPT-4) and The Health Care Financing Administration (HCFA)/Healthcare Common Procedural Coding System (HCPCS) were utilized to identify adult $(\geq 18)$ patients with oral cavity cancers (Additional file 1: Table 1) with a defined treatment modality (surgery alone, surgery + radiotherapy or surgery + concurrent chemoradiotherapy -CCR-) between January 1, 2010 and December 31, 2012. Follow-up data was available through 2013 and 2014.

\section{Statistical methods}

Characteristics of those in the cohort were assessed as continuous and categorical variables, using the mean/ standard deviation and frequency/percentages, respectively. To quantify comorbidities, the Charlson-Deyo Comorbidity Index Score $[9,10]$. was calculated based on diagnoses occurring within the year prior to the date of cancer diagnosis. Pearson's Chi-square test was used to evaluate guideline-recommended processes of care (imaging of the head and neck and chest, thyroid function testing and multidisciplinary consultation). All analyses were performed using SAS 9.4 (SAS Institute, Cary, $\mathrm{NC}$.

\section{Guideline-recommended processes}

The number of patients who underwent imaging of the head and neck (Computer Tomography -CT- scan, Magnetic Resonance Imaging -MRI- or, ultrasound) and chest (x-ray, CT scan or MRI) prior to the initiation of the first treatment modality was tabulated during the time period within 2 months of the oral cavity cancer diagnosis date 
Table 1 Characteristics of the oral cavity cancer study population with a defined treatment modality

\begin{tabular}{|c|c|c|c|c|}
\hline Characteristic & $\begin{array}{l}\text { Surgery }(N=1674 \\
-60.8 \%-)\end{array}$ & $\begin{array}{l}\text { Surgery with adjuvant radiation } \\
(\mathrm{N}=518-18.8 \%)\end{array}$ & $\begin{array}{l}\text { Surgery with } \\
\text { adjuvant CCRT } \\
(\mathrm{N}=560-20.4 \%)\end{array}$ & $\begin{array}{l}\text { Overall } \\
(\mathrm{N}=2752)\end{array}$ \\
\hline Mean age (SD) & $61.8(13.2)$ & $61.1(12.5)$ & $58.7(10.7)$ & $61.0(12.7)$ \\
\hline Male (\%) & $1017(60.75 \%)$ & $320(61.78 \%)$ & $406(72.50 \%)$ & $1,743(63.34 \%)$ \\
\hline \multicolumn{5}{|l|}{ Geographic Region (\%)* } \\
\hline Northeast & $323(19.90 \%)$ & 109 (21.29\%) & $111(20.33 \%)$ & $543(20.25 \%)$ \\
\hline North Central & $418(25.75 \%)$ & $145(28.32 \%)$ & $160(29.30 \%)$ & $723(26.97 \%)$ \\
\hline South & $538(33.15 \%)$ & 159 (31.05\%) & $176(32.23 \%)$ & $873(32.56 \%)$ \\
\hline West & $344(21.20 \%)$ & $99(19.34 \%)$ & $99(18.13 \%)$ & $542(20.22 \%)$ \\
\hline \multicolumn{5}{|l|}{ Comorbidities (\%) } \\
\hline Alcohol abuse & $41(2.45 \%)$ & 15 (2.90\%) & $27(4.82 \%)$ & 83 (3.02\%) \\
\hline Peripheral vascular disease & $66(3.94 \%)$ & $18(3.47 \%)$ & $22(3.93 \%)$ & $106(3.85 \%)$ \\
\hline Chronic pulmonary disease & $242(14.46 \%)$ & $71(13.71 \%)$ & $103(18.39 \%)$ & $416(15.12 \%)$ \\
\hline Moderate or severe liver disease & $3(0.18 \%)$ & $0(0 \%)$ & $2(0.36 \%)$ & $5(0.18 \%)$ \\
\hline \multicolumn{5}{|l|}{ Charlson/Deyo Comorbidity Index (\%) } \\
\hline 1 & 1000 (59.74\%) & 253 (48.84\%) & 201 (35.89\%) & 1454 (52.83\%) \\
\hline 2 & 432 (25.81\%) & 168 (32.43\%) & $226(40.36 \%)$ & 826 (30.01\%) \\
\hline 3 & $142(8.48 \%)$ & $58(11.20 \%)$ & $90(16.07 \%)$ & 290 (10.54\%) \\
\hline$\geq 4$ & 100 (5.97\%) & 39 (7.53\%) & $43(7.68 \%)$ & $182(6.61 \%)$ \\
\hline
\end{tabular}

Presence of comorbidities is assessed 1 year prior to cancer diagnosis

${ }^{*}$ Total number of patients are $2681,1623,512,546$ and 2681 for surgery only, surgery with adjuvant radiation, surgery with adjuvant CCRT and overall respectively

(as defined by the date of the first pathology report with a site-specific cancer diagnosis). The number of patients who received a PET scan during the same time period was also included.

In the subset of patients who received radiotherapy, we assessed whether patients had at least one set of TFTs in each available full year of post-radiation follow-up.

Multidisciplinary consultation occurrence was assessed as a dichotomous variable which indicated if patients had received a consultation with more than one specialty (medical oncology, radiation oncology or surgery) during the 6 months prior to and 3 months after initiation of first treatment modality.

\section{Costs associated with guideline-recommended processes of care}

Costs were summarized using the MarketScan financial variable 'PAY' which represents gross payments in U.S. dollars to a provider for a service. Payment equals the amount eligible for payment under the medical plan terms after applying rules such as discounts, but before applying $\mathrm{COB}$, copayments, and deductibles.

\section{Length of stay (LOS) and G-tube insertion}

In a sub-cohort in which length of stay (LOS) data was available, the mean LOS and discharge disposition were assessed (DAYS for LOS and DSTATUS for discharge disposition in MarketScan fields). Although not included as a formal indicator for QoC in the cited guidelines $[3,4,11]$, LOS was considered an important related outcome. G-tube insertion was used as a surrogate for treatment toxicity [12]. Therefore, a subgroup analysis looking at the rate of G-tube insertion within each modality treatment during the first year of treatment was obtained. G-tube rates by treatment modality were assessed using a Chi-square for trend with statistical significance being reported for $p<0.05$.

\section{Results}

\section{Patients with oral cavity cancer with a defined treatment modality}

There was a total of 2752 patients diagnosed with an oral cavity cancer identified using the MarketScan database in a 2 -year period. The majority of patients were treated with surgery alone $(60.8 \%)$. Patients were 61 years old on average; most were male (63.3\%) and from the Southern United States (32.6\%). Fifteen percent had chronic pulmonary disease and nearly half had Charlson-Deyo comorbidity index of 1 (Table 1).

\section{Guideline-recommended processes of care}

Head and neck and chest imaging were obtained in $60 \%$ and $62.5 \%$ of patients respectively in patients treated between January 1, 2010 and December 31, 2012 and subsequently followed through 2013 and 2014. Noteworthy, $40 \%$ of the chest imaging corresponded to 
Table 2 Compliance with guideline-recommended processes of care

\begin{tabular}{|c|c|}
\hline Guideline-recommended processes & $\begin{array}{l}\text { No.Patients } \\
(\mathrm{N}=2,752)\end{array}$ \\
\hline \multicolumn{2}{|l|}{ Multidisciplinary consultation $\neq$} \\
\hline (2 specialties: Med Onc, Rad Onc, or Surgery*) & $513(18.6 \%)$ \\
\hline Head and Neck Imaging & $1653(60 \%)$ \\
\hline Northeast & $328(60.4 \%)$ \\
\hline North Central & $463(64 \%)$ \\
\hline South & $510(58.4 \%)$ \\
\hline West & $\begin{array}{l}304(56.1 \%) \\
p=0.026\end{array}$ \\
\hline $\begin{array}{l}\text { Chest Imaging } \\
\text { Northeast } \\
\text { North Central } \\
\text { South } \\
\text { West }\end{array}$ & $\begin{array}{l}1,721(62.54 \%) \\
353(65 \%) \\
474(65.5 \%) \\
540(61.8 \%) \\
308(56.8 \%) \\
p=0.007\end{array}$ \\
\hline Patients with at least one TFTS following treatment† & $586 / 1,078(54.3 \%)$ \\
\hline Patients with Perfect Adherence ${ }^{a}$ & $329 / 1,078(30.5 \%)$ \\
\hline \multicolumn{2}{|c|}{$\begin{array}{l}\text { Time frame for assessing compliance with imaging is }-/+ \text { two months of the } \\
\text { cancer diagnosis date }\end{array}$} \\
\hline \multicolumn{2}{|c|}{$\begin{array}{l}\text { ₹ Patients with at least } 1 \text { consultation during the } 6 \text { months before to } 3 \text { months } \\
\text { after surgery }\end{array}$} \\
\hline \multicolumn{2}{|l|}{${ }^{*}$ Surgery/ENT/Plastic/Maxillofacial surgery } \\
\hline \multicolumn{2}{|l|}{${ }^{\dagger}$ Patients with a Radiation or CCRT Treatment Modality only } \\
\hline \multicolumn{2}{|l|}{$\begin{array}{l}\text { a Perfect adherence captures patients who have had a } \\
\text { TFTS in each available year of post-radiation follow-up }\end{array}$} \\
\hline $\begin{array}{l}\text { Note: The denominator in the different geographic regio } \\
\text { is the same as the Overall column in Table } 1\end{array}$ & \\
\hline
\end{tabular}
is the same as the Overall column in Table 1
Table 3 Costs Associated with guideline-recommended processes of care

\begin{tabular}{ll}
\hline Guideline-recommended processes & ${\text { Mean } \operatorname{cost}^{\mathbf{b}} \text { (SD) }}^{\text {Head and Neck Imaging }}$ \\
CT & $716.4(738.5)$ \\
MRI & $1286.3(1417.8)$ \\
Chest Imaging & \\
CT & $555.6(547.3)$ \\
PET Scan & $2117.0(1698.9)$ \\
Thyroid function testing $^{\text {a }}$ & $104.1(124.1)$
\end{tabular}

${ }^{a}$ Costs are computed for patients with perfect adherence. TFTS applies to patients who received radiotherapy

${ }^{\mathrm{b}}$ (\$USD)

radiographies. Differences in the proportion of patients who underwent head and neck imaging were observed when the data were analyzed by region (Table 2). Differences in chest imaging were also present according to region (Table 2). At least one TFT was done in $54.4 \%$ of the patients who received radiation treatment, and $30.5 \%$ had an annual TFTs after radiotherapy for every possible full calendar year from radiotherapy in which they were eligible to have a TFTs. Only $18.6 \%$ received multidisciplinary consultation (Table 2).

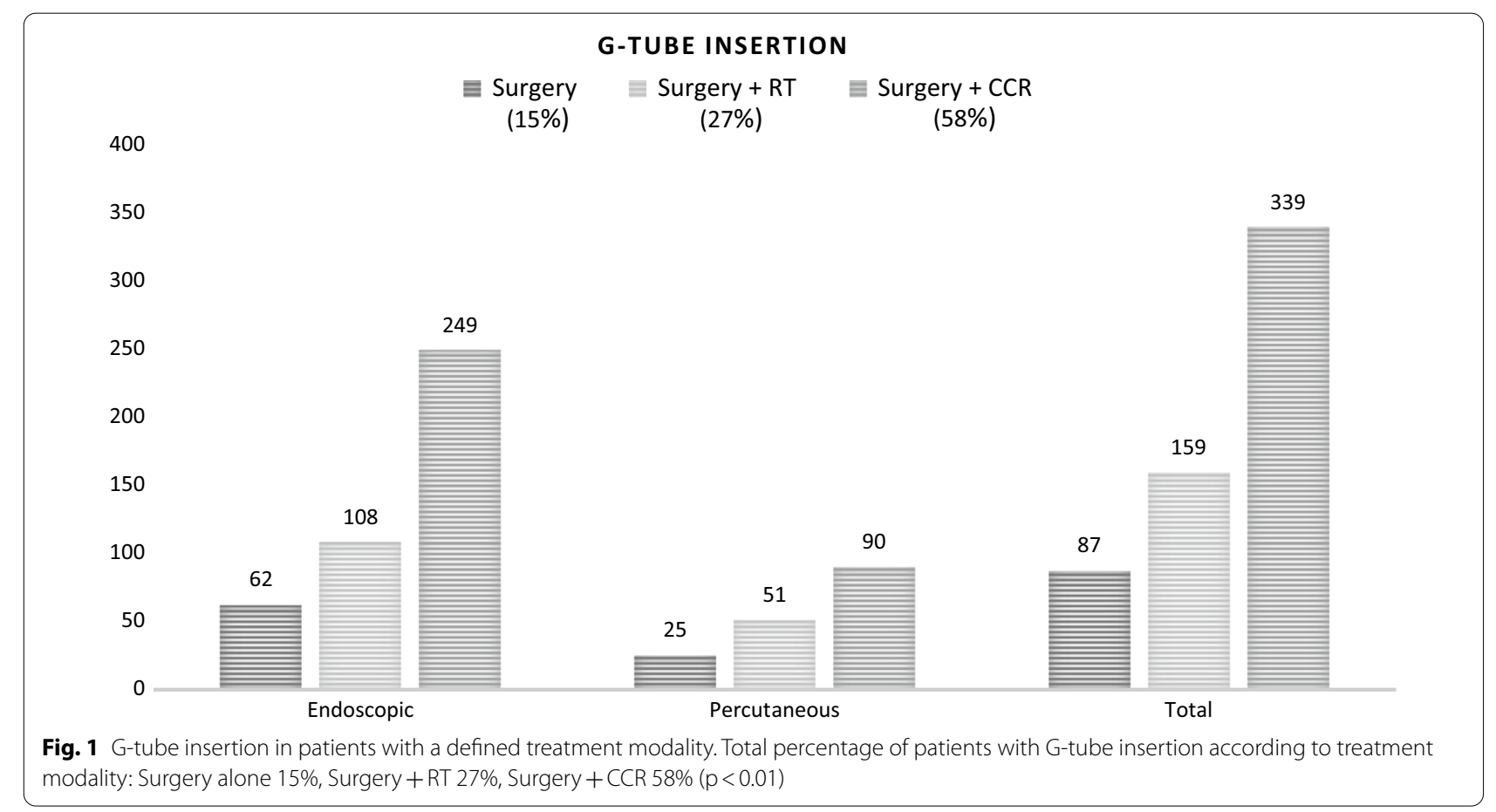




\section{Costs Associated with guideline-recommended processes of care}

Mean costs for a CT scan and MRI of the head and neck were $\$ 716$ and $\$ 1,286$ respectively. The mean cost for a CT chest scan was $\$ 555$ and PET scans had a mean cost of $\$ 2,117$. Cost for TFTs averaged $\$ 104$ per year (Table 3).

\section{Length of stay (LOS) and G-tube insertion}

A total of 281 of the patients had available LOS and discharge data for their surgical episode of care. Among them, the median inpatient length of stay was found to be 4 days and $77 \%$ of the patients were discharged to home with self-care. In $16 \%$ of cases, the patient was discharged with additional nursing care.

In the first year after treatment initiation, 585 (21.2\%) of the oral cavity cancer patients received a G-tube placement. The majority of G-tubes were inserted endoscopically. Rates of gastrostomy tubes were $58 \%$ in patients who received surgery and adjuvant chemoradiotherapy, $27 \%$ in the surgery and adjuvant radiotherapy group and $15 \%$ in patients undergoing surgery alone. Patients who underwent triple modality had the highest rates of G-tube insertion $(p<0.01$; Fig. 1$)$.

\section{Discussion}

Delivering high quality care has recently become the overarching objective in many healthcare systems. Accordingly, there has been growing recognition of the value in measuring QoC using processes of care, alongside the more traditional outcomes metrics (mortality and morbidity) $[13,14]$. Although robust head and neck oncology guidelines exist [3-5], there are a limited number of large scale population-based reports analyzing healthcare providers adherence to these guidelines [3, 4]. Employing a large database of oral cavity cancer patients treated surgically, we evaluated adherence to the guideline-recommended processes of care. We found that concordance with the selected best practices were limited and had significant geographic variation.

Preoperative imaging had the highest adherence rates, with $60 \%$ for head and neck and $62.5 \%$ for chest from a cohort of 2,752 patients. The slightly higher adherence in chest imaging (CT, MRI or chest $x$-ray) could potentially be attributed to the anesthesiology preoperative workup, where chest $\mathrm{x}$-rays are frequently ordered. This hypothesis is supported by the fact that $40 \%$ of the chest images corresponded to radiographies. Previous reports have shown disparities in preoperative imaging; Hessel et al. [13], examined 116 early tongue cancer patients managed at MD Anderson Cancer Center (MDACC), and noted that only $67.2 \%$ had preoperative head and neck CT scans or MRI. Using the Ontario Cancer Registry and capturing
5,720 patients with squamous cell carcinomas of the head and neck, Eskander et al. [15] found that preoperative head and neck and chest imaging was performed in $71.8 \%$ and $82.5 \%$ of patients, respectively. A more recent experience which included patients with laryngeal carcinomas using the MarketScan database, Britt et al. [16] observed that $52 \%$ of 8,392 patients (excluding early glottic cancers) had pre-treatment imaging. Our findings are in keeping with all of these studies, and using a large database of oral cavity cancers, we confirm that adherence rates are less than perfect, regardless of jurisdiction or cancer subsite.

Geographically differences with higher adherence rates reported in Canadian reports, specifically in Ontario, likely reflect an increased regionalization of care where most patients are referred to high-volume oncologic centers [17]. In the present study, we also found geographical U.S. differences in preoperative imaging. North Central and South regions, and North Central and the West, differed in head and neck imaging while North East and West and North Central and West, had differences in chest imaging. This warrants further assessment, but may be related to differing referral patterns, regional insurance providers and access to care. In the U.S., referral patterns vary significantly due to differing insurance providers' networks and geographic availability of head and neck cancer care specialists. Nonetheless, both in Canada and the U.S., there is a push towards standardization of care processes, which is albeit still somewhat heterogeneous among centers. PET imaging demonstrated large variations in care that are, in part, related to differing evidence on the role of the technology as well as varying insurance coverage rates for this imaging modality.

The deleterious impact of radiotherapy for head and neck cancer on thyroid function is well known, with radiation-induced hypothyroidism occurring in up to $53 \%$ of patients [18]. Despite this, only $54.3 \%$ of 1,078 patients receiving adjuvant radiation had posttreatment TFTs. Rates were even lower in a laryngeal cohort16, in which only $31.9 \%$ had their thyroid function assessed after treatment. Our analysis showed that rates of thyroid testing declined even more during patients' follow-up, as $30.5 \%$ of individuals had a TFTs for each post-radiation treatment year. In cases where follow-up relies on more than one sub-specialty, the shared responsibility of ordering studies may lead to uncertainty around who should order the test, and monitoring if the TFTs have been completed.

Decision making through multidisciplinary consultation (MDT) not only improves patients' survival $[19,20]$ but also increases the adherence to other processes of care $[21-23,15$ 
We are aware that G-tube insertion is not a QoC indicator. It is however an important and impactful process of care that was reliably coded in the data. As such we chose to describe its use in this population which typically requires a relatively low rate of G-tube insertion. Our data does add value to the literature in that there is less reporting of G-tube use in oral cavity cancer patients compared to oropharynx cancer $[24,24-26,12]$.

Previous reports about QoC in oral cavity cancer patients addressed the adherence of healthcare providers to evidence-based guidelines [13, 27, 7, 16, 15, 14, 28

Our findings confirm the need to implement strategies to promote adherence to guidelines. Facilitating feedback between non-academic and academic healthcare facilities through multidisciplinary treatment conferences could potentially improve treatment quality $[20,29]$. Similar to cancer "roadmaps" for head and neck cancer survivors as part of a comprehensive survivorship program [30, 31], checklists containing evidence-based recommendations can be developed for patients with head and neck cancer and distributed in non-academic centers in the active follow-up phase prior to transitioning into survivorship programs. Such recommendations could also be included in the electronic medical record as 'force functions' to ensure adherence. Treatment care plans can also be given to patients to empower them to participate in their care.

Fortunately, perfect adherence to these guidelines would minimally increase costs based on our cost analysis, with the appropriate imaging and bloodwork costing less than $\$ 2000-3000$ per patient in the first 5 years of follow up. The cost variation depends on the imaging modality chosen, with PET scans significantly increasing costs. Regionalization of head and neck cancer care, with proven improvements in outcomes[17, 32], can also represent an intervention to promote adherence to guidelines and improve QoC, though both geography and the insurance landscape may limit its implementation in the US. Furthermore, regionalization significantly increases patient and caregiver travel burden. Head and neck cancer research should therefore continue to study, report and improve quality of care processes given the large variations and imperfect adherence to guidelines recommendations.

\section{Conclusions}

Adherence to evidence-based practices was low based on the database coding. These data suggest a potential to improve adherence and increase the routine use of practices delineated in national clinical practice guidelines. This study should be considered by healthcare providers and efforts should be maximized to follow the processes of care which have proven to impact on patient's outcomes.

\section{Abbreviations}

TFT: Thyroid-function testing; QoC: Quality of Care; NCCN: National Comprehensive Cancer Network; NICE: National Institute for Health and Care Excellence; CCO: Cancer Care Ontario; ICD-9-CM: International Classification of Diseases, Ninth Revision, Clinical Modification; CPT-4: The Current Procedural Terminology, 4th Edition; HCFA: The Health Care Financing Administration (HCFA); HCPCS: Healthcare Common Procedural Coding System; CCR: Concurrent chemoradiotherapy; CT: Computer tomography; MRI: Magnetic Resonance Imaging; LOS: Length of stay; MDACC: MD Anderson Cancer Center; MDT: Multidisciplinary consultation.

\section{Supplementary Information}

The online version contains supplementary material available at https://doi. org/10.1186/s12903-021-01616-x.

Additional file 1: Supplemental Table 1. Otolaryngology Head and Neck Surgery Procedures captured by coding.

\section{Acknowledgements}

None.

\section{Authors' contributions}

AE: Made substantial contributions to the conception and design of the work, acquisition, analysis and interpretation of data, approved the submitted version and agreed both to be personally accountable for the author's own contributions and to ensure that questions related to the accuracy or integrity of any part of the work, even ones in which the author was not personally involved, are appropriately investigated, resolved, and the resolution documented in the literature. AS: Made substantial contributions to the conception and design of the work, acquisition, analysis and interpretation of data, approved the submitted version and agreed both to be personally accountable for the author's own contributions and to ensure that questions related to the accuracy or integrity of any part of the work, even ones in which the author was not personally involved, are appropriately investigated, resolved, and the resolution documented in the literature. JS: Made substantial contributions to the conception and design of the work, approved the submitted version and agreed both to be personally accountable for the author's own contributions and to ensure that questions related to the accuracy or integrity of any part of the work, even ones in which the author was not personally involved, are appropriately investigated, resolved, and the resolution documented in the literature. KD: Made substantial contributions to the conception and design of the work, approved the submitted version and agreed both to be personally accountable for the author's own contributions and to ensure that questions related to the accuracy or integrity of any part of the work, even ones in which the author was not personally involved, are appropriately investigated, resolved, and the resolution documented in the literature. MC: Made substantial contributions to the conception and design of the work, approved the submitted version and agreed both to be personally accountable for the author's own contributions and to ensure that questions related to the accuracy or integrity of any part of the work, even ones in which the author was not personally involved, are appropriately investigated, resolved, and the resolution documented in the literature. NG: Made substantial contributions to the conception and design of the work, approved the submitted version and agreed both to be personally accountable for the author's own contributions and to ensure that questions related to the accuracy or integrity of any part of the work, even ones in which the author was not personally involved, are appropriately investigated, resolved, and the resolution documented in the literature. DLW: Made substantial contributions to the conception and design of the work, approved the submitted version and agreed both to be personally accountable for the author's own contributions and to ensure that questions related to the accuracy or integrity of any part of the work, even ones in which the author was not personally involved, are appropriately investigated, resolved, and the resolution documented in the literature. KS: Made substantial contributions to the conception and design of the work, approved the submitted version and agreed both to be personally accountable for the author's own contributions and to ensure that questions related to the accuracy or integrity of any part of the work, even ones in which the author was not personally involved, are appropriately investigated, 
resolved, and the resolution documented in the literature. NDG: Made substantial contributions to the conception and design of the work, approved the submitted version and agreed both to be personally accountable for the author's own contributions and to ensure that questions related to the accuracy or integrity of any part of the work, even ones in which the author was not personally involved, are appropriately investigated, resolved, and the resolution documented in the literature. RW: Made substantial contributions to the conception and design of the work, approved the submitted version and agreed both to be personally accountable for the author's own contributions and to ensure that questions related to the accuracy or integrity of any part of the work, even ones in which the author was not personally involved, are appropriately investigated, resolved, and the resolution documented in the literature. SSK: Made substantial contributions to the conception and design of the work, approved the submitted version and agreed both to be personally accountable for the author's own contributions and to ensure that questions related to the accuracy or integrity of any part of the work, even ones in which the author was not personally involved, are appropriately investigated, resolved, and the resolution documented in the literature. SC: Made substantial contributions to the conception and design of the work, approved the submitted version and agreed both to be personally accountable for the author's own contributions and to ensure that questions related to the accuracy or integrity of any part of the work, even ones in which the author was not personally involved, are appropriately investigated, resolved, and the resolution documented in the literature. DC: Made substantial contributions to the conception and design of the work, approved the submitted version and agreed both to be personally accountable for the author's own contributions and to ensure that questions related to the accuracy or integrity of any part of the work, even ones in which the author was not personally involved, are appropriately investigated, resolved, and the resolution documented in the literature. WL: Made substantial contributions to the conception and design of the work, approved the submitted version and agreed both to be personally accountable for the author's own contributions and to ensure that questions related to the accuracy or integrity of any part of the work, even ones in which the author was not personally involved, are appropriately investigated, resolved, and the resolution documented in the literature. VM: Made substantial contributions to the conception and design of the work, approved the submitted version and agreed both to be personally accountable for the author's own contributions and to ensure that questions related to the accuracy or integrity of any part of the work, even ones in which the author was not personally involved, are appropriately investigated, resolved, and the resolution documented in the literature. All authors have read and approved the manuscript.

\section{Funding}

This was a self-funded study.

\section{Availability of data and materials}

Availability of data and materials will be provided upon request.

\section{Declarations}

\section{Ethics approval and consent to participate}

This study was deemed exempt from Institutional Review Board oversight at Duke Medicine as it focuses on de-identified health information (Pro00068570). No administrative permissions and/or licenses were acquired by the research team/authors to access the data used in our research.

\section{Consent for publication}

Not applicable.

\section{Competing interests}

Authors state they have no interests to declare.

\section{Author details}

${ }^{1}$ Department of Otolaryngology-Head and Neck Surgery, Sunnybrook Health Sciences Centre and the Odette Cancer Centre, University of Toronto, 2075 Bayview Ave., M1-102, Toronto, ON M4N 3M5, Canada. ${ }^{2}$ Department of Otolaryngology, Harvard Medical School, Boston, MA, USA. ${ }^{3}$ Department of Otolaryngology-Head and Neck Surgery, College of Medicine, The Pennsylvania State University, Hershey, PA, USA. ${ }^{4}$ Department of Head and Neck Surgery \&
Communication Sciences, Duke University Medical Center, Durham, NC, USA. ${ }^{5}$ Department of Head and Neck Surgery, University of Texas MD Anderson Cancer Center, Houston, USA. ${ }^{6}$ Department of Otolaryngology-Head and Neck Surgery, University of Minnesota, Minneapolis, MN, USA. ${ }^{7}$ Clinical Research Unit, Duke University, Durham, NC, USA. ${ }^{8}$ Department of Otorhinolaryngology-Head and Neck Surgery, Montefiore Medical Center, Bronx, NY, USA.

Received: 28 January 2021 Accepted: 9 May 2021

Published online: 17 May 2021

\section{References}

1. Berwick DM. A user's manual for the IOM's "Quality Chasm" report. Health Aff (Millwood). 2002;21(3):80-90. https://doi.org/10.1377/hlthaff.21.3.80.

2. Donabedian A. The quality of care. How can it be assessed? JAMA. 1988;260(12):1743-8.

3. Adelstein D, Gillison ML, Pfister DG, et al. NCCN Guidelines Insights: Head and Neck Cancers, Version 2.2017. J Natl Compr Cancer Netw. 2017;15(6):761-70. https://doi.org/10.6004/jnccn.2017.0101.

4. National Institute of Clinical Excellence. Improving Outcomes in Head and Neck Cancers: The Manual. National Institute for Health and Care Excellence, London (2015). http://www.nice.org.uk/guidance/csghn/ resources/improving-outcomes-in-head-and-neck-cancers.

5. Gilbert R, Devries-Aboud M, Winquist E, Waldron J, McQuestion M $H$ and NDSG. The management of head and neck cancer in Ontario. Cancer Care Ontario. 2009, series 5-3 (Program in Evidence-based Care Evidence-Based Series).

6. Motz K, Chang H-Y, Quon H, Richmon J, Eisele DW, Gourin CG. Association of Transoral Robotic Surgery With Short-term and Long-term Outcomes and Costs of Care in Oropharyngeal Cancer Surgery. JAMA Otolaryngol Neck Surg. 2017;143(6):580. https://doi.org/10.1001/jamaoto.2016.4634.

7. Day AT, Chang H-Y, Quon H, et al. Treatment, short-term outcomes, and costs associated with larynx cancer care in commercially insured patients. Laryngoscope. 2018;128(1):91-101. https://doi.org/10.1002/lary.26717.

8. Jang DW, Abraham C, Cyr DD, Schulz K, Abi Hachem R, Witsell DL. Balloon Catheter Dilation of the Sinuses: A 2011-2014 MarketScan Analysis. Otolaryngol Neck Surg. 2018;159(6):1061-7. https://doi.org/10.1177/01945 99818791811.

9. Charlson ME, Pompei P, Ales KL, MacKenzie CR. A new method of classifying prognostic comorbidity in longitudinal studies: development and validation. J Chronic Dis. 1987;40(5):373-83.

10. Deyo RA, Cherkin DC, Ciol MA. Adapting a clinical comorbidity index for use with ICD-9-CM administrative databases. J Clin Epidemiol. 1992;45(6):613-9.

11. Gilbert R, Devries-Aboud M, Winquist E, Waldron J M, M. Head and Neck Disease Site Group. The management of head and neck cancer in Ontario. Toronto (ON): Cancer Care Ontario; 2009 Dec 15 [In review 2015 Nov]. Program in Evidence-based Care EvidenceBased Series No.:5-3 IN REVIEW.

12. Dong Y, Ridge JA, Li T, et al. Long-term toxicities in 10-year survivors of radiation treatment for head and neck cancer. Oral Oncol. 2017;71:122-8. https://doi.org/10.1016/j.oraloncology.2017.05.009.

13. Hessel AC, Moreno MA, Hanna EY, et al. Compliance with quality assurance measures in patients treated for early oral tongue cancer. Cancer. 2010;116(14):3408-16. https://doi.org/10.1002/cncr.25031.

14. Irish J, Eskander A. The importance and challenges of a specialty-specific National Surgical Quality Improvement Program for Head and Neck Surgery. JAMA Otolaryngol Head Neck Surg. 2016;142(4):328-9. https:// doi.org/10.1001/jamaoto.2016.0127.

15. Eskander A, Monteiro E, Irish J, et al. Adherence to guideline-recommended process measures for squamous cell carcinoma of the head and neck in Ontario: Impact of surgeon and hospital volume. Head Neck. 2016;38(Suppl 1):E1987-92. https://doi.org/10.1002/hed.24364.

16. Britt CJ, Chang H-Y, Quon H, et al. Quality indicators of laryngeal cancer care in commercially insured patients. Laryngoscope. 2017;127(12):280512. https://doi.org/10.1002/lary.26728.

17. Eskander A, Irish J, Groome PA, et al. Volume-outcome relationships for head and neck cancer surgery in a universal health care system. Laryngoscope. 2014;124(9):2081-8. https://doi.org/10.1002/lary.24704. 
18. Boomsma MJ, Bijl HP, Langendijk JA. Radiation-induced hypothyroidism in head and neck cancer patients: a systematic review. Radiother Oncol. 2011;99(1):1-5. https://doi.org/10.1016/j.radonc.2011.03.002.

19. Nguyen NP, Vos $P$, Lee $H$, et al. Impact of tumor board recommendations on treatment outcome for locally advanced head and neck cancer. Oncology. 2008;75(3-4):186-91. https://doi.org/10.1159/000163058.

20. Lewis CM, Nurgalieva Z, Sturgis EM, Lai SY, Weber RS. Improving patient outcomes through multidisciplinary treatment planning conference. Head Neck. 2016;38(Suppl 1):E1820-5. https://doi.org/10.1002/hed. 24325.

21. Kelly SL, Jackson JE, Hickey BE, Szallasi FG, Bond CA. Multidisciplinary clinic care improves adherence to best practice in head and neck cancer. Am J Otolaryngol. 2013;34(1):57-60. https://doi.org/10.1016/j.amjoto. 2012.08.010.

22. Friedland PL, Bozic B, Dewar J, Kuan R, Meyer C, Phillips M. Impact of multidisciplinary team management in head and neck cancer patients. $\mathrm{Br}$ J Cancer. 2011;104(8):1246-8. https://doi.org/10.1038/bjc.2011.92.

23. Starmer H, Sanguineti G, Marur S, Gourin CG. Multidisciplinary head and neck cancer clinic and adherence with speech pathology. Laryngoscope. 2011;121(10):2131-5. https://doi.org/10.1002/lary.21746.

24. Varma VR, Eskander A, Kang SY, et al. Predictors of gastrostomy tube dependence in surgically managed oropharyngeal squamous cell carcinoma. Laryngoscope. 2019;129(2):415-21. https://doi.org/10.1002/lary. 27290.

25. Christianen MEMC, Verdonck-de Leeuw IM, Doornaert $P$, et al. Patterns of long-term swallowing dysfunction after definitive radiotherapy or chemoradiation. Radiother Oncol. 2015;117(1):139-44. https://doi.org/10. 1016/j.radonc.2015.07.042.

26. Peach MS, Trifiletti DM, Vachani C, et al. Patient-reported outcomes in head and neck cancer: prospective multi-institutional patient-reported toxicity. Patient Relat Outcome Meas. 2018;9:245-52. https://doi.org/10. 2147/PROM.S153919.

27. Lewis CM, Hessel AC, Roberts DB, et al. Prereferral head and neck cancer treatment: compliance with national comprehensive cancer network treatment guidelines. Arch Otolaryngol Head Neck Surg. 2010;136(12):1205-11. https://doi.org/10.1001/archoto.2010.206.

28. Eskander A, Goldstein DP, Irish JC. Health Services Research and Regionalization of Care-From Policy to Practice: the Ontario Experience in Head and Neck Cancer. Curr Oncol Rep. 2016;18(3):19. https://doi.org/10. 1007/s11912-016-0500-6.

29. Shellenberger TD, Weber RS. Multidisciplinary team planning for patients with head and neck cancer. Oral Maxillofac Surg Clin North Am. 2018;30(4):435-44. https://doi.org/10.1016/j.coms.2018.06.005.

30. Nekhlyudov L, Lacchetti C, Davis NB, et al. Head and Neck Cancer Survivorship Care Guideline: American Society of Clinical Oncology Clinical Practice Guideline Endorsement of the American Cancer Society Guideline. J Clin Oncol. 2017;35(14):1606-21. https://doi.org/10.1200/JCO.2016. 71.8478 .

31. Cohen EEW, LaMonte SJ, Erb NL, et al. American Cancer Society Head and Neck Cancer Survivorship Care Guideline. CA Cancer J Clin. 2016;66(3):203-39. https://doi.org/10.3322/caac.21343.

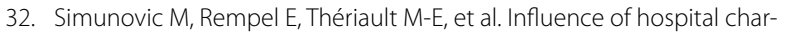
acteristics on operative death and survival of patients after major cancer surgery in Ontario. Can J Surg. 2006;49(4):251-8.

\section{Publisher's Note}

Springer Nature remains neutral with regard to jurisdictional claims in published maps and institutional affiliations.
Ready to submit your research? Choose BMC and benefit from:

- fast, convenient online submission

- thorough peer review by experienced researchers in your field

- rapid publication on acceptance

- support for research data, including large and complex data types

- gold Open Access which fosters wider collaboration and increased citations

- maximum visibility for your research: over 100M website views per year

At BMC, research is always in progress.

Learn more biomedcentral.com/submissions 